\title{
The Value of Information in an Online Consumer Electronics Market*
}

\author{
Michael R. Baye \\ Indiana University (mbaye@indiana.edu) \\ John Morgan \\ University of California-Berkeley (morgan@haas.berkeley.edu) \\ Patrick Scholten \\ Indiana University (pscholte@indiana.edu) \\ Invited paper prepared for the Journal of Public Policy $\mathscr{G}$ Marketing \\ special issue on Marketing's Information Technology Revolution: \\ Implications for Consumer Welfare and Economic Performance. \\ Revised August 2002
}

\begin{abstract}
Consumers buying electronics products at the lowest prices on Shopper.com during 2000 and 2001 saved an average of 16 percent, compared to purchasing at the average listed price. Consistent with a variety of theories, the value of information depends on the size of the market. When two firms list prices, consumers save $11 \%$ by purchasing at the lowest price rather than the average price. These savings jump to $20 \%$ when more than 30 firms list prices. However, these potential savings accrue only to consumers on the "right side" of the "digital divide."
\end{abstract}

JEL Numbers: D4, D8, M3, L13.

Keywords: Internet, Information, Price Dispersion, Digital Divide.

${ }^{*}$ We are grateful to David Sappington and two referees for providing very helpful comments on an earlier draft. 


\section{Introduction}

Information has come a long way since the day that Nobel Laureate George Stigler noted it "...occupies a slum dwelling in the town of economics" (1961, p. 213). Today more than ever, information plays an increasingly important role in the lives of peo-

ple around the world. The Internet, in particular, has transformed how goods and services are bought and sold between consumers (C2C), between businesses and consumers (B2C), and between businesses (B2B). Two Internet institutions have been especially influential in facilitating trade among market participants: electronic auctions and price comparison services. While there are important differences between these institutions, both provide price information. Information about prices is a valuable resource.

While it seems apparent that information on the Internet is valuable to those with access, it is virtually impossible to quantify all of the benefits the "information revolution" has brought consumers. Nonetheless, quantitative estimates of these benefits are necessary if one is to reasonably judge policy proposals for improving Internet access for those on the wrong side of the so-called "digital divide." This paper quantifies one small but measurable component of these benefits: the value of information provided by Internet price comparison sites. Our main finding is that consumers without access to such a site have to spend about $16 \%$ more for consumer electronics products compared to consumers on the right side of the digital divide.

The paper is motivated by a host of recent papers demonstrating that the prices 
of seemingly identical products sold on the Internet vary substantially even though it is allegedly very easy for consumers to engage in comparison shopping. For instance, Baye, Morgan, and Scholten (2001) examined nearly 4 million price quotes for over 1,000 electronics products sold at the price comparison site, Shopper.com, and found that the average range in prices over an 8-month period spanning the years 2000 and 2001 was about $\$ 120$, compared to the average selling price of $\$ 510 .{ }^{1}$ Perhaps more surprising is that the observed price dispersion persisted over an 8-month period, despite the fact that consumers utilizing Shopper.com obtain a list of the prices that different merchants charge for the same product and, with a simple click of the mouse, can identify the merchant on the list that charges the lowest price.

As Internet markets mature, one would expect more and more shoppers and firms to use Internet price comparison sites. Indeed, between December 1998 and August 2000, the percentage of households in the US with Internet access increased from 26.2 percent to 41.5 percent. $^{2}$ According to the Census Bureau, there were nearly 10,000

${ }^{1}$ Estimates of price dispersion for homogeneous products sold on the Internet vary widely. Studies that tend to find very high levels of dispersion in Internet markets include Bailey (1998a, 1998b); Brynjolfsson and Smith (2000a); Clemons, Hann, and Hitt (2000); Smith (2001); Clay, Krishnan, and Wolff (2001); and Clay and Tay (2001). In contrast, relatively narrow distributions of prices were observed by Ellison and Ellison (2001) for computer memory; Brown and Goolsbee (2002) in 'thick' markets for life insurance; and Morton, Zettelmeyer, and Silva-Risso (2001) for cars. Other studies that examine a diverse mix of homogeneous products and find intermediate levels of price dispersion include Pan, Ratchford, and Shankar (2001) and Scholten and Smith (2002). Recently, Baye, Morgan, and Scholten (2001) provide evidence that these differences stem largely from differences in the numbers of firms listing prices for the products.

2 See the on-line document, "Falling Through the Net: Defining the Digital Divide," U.S. Department of Commerce, National Telecommunications and Information, www.ntia.doc.gov/ntiahome/digitaldivide/index.html. 
consumer electronics retail establishments in the United States in 1997. ${ }^{3}$ Each of these stores could, in principle, advertise their prices on price comparison sites such as Shopper.com. ${ }^{4}$ The classical view is that maturing Internet markets will cause prices to decline toward marginal cost. ${ }^{5}$ This view implies that the long-run value to consumers of the information obtained from price comparison sites will converge to zero: In the absence of any price dispersion, consumers can purchase goods at marginal cost irrespective of whether they utilize a price comparison site. ${ }^{6}$

A recent paper by Baye and Morgan (2001) challenges this view. They show that the classical argument fails to account for the fixed costs typically required for parties to transmit and acquire information over the Internet. These costs may include the monthly costs of maintaining servers or, in the case of a price comparison site, the monthly fees that Shopper.com charges firms to list prices at their site. Baye and Morgan show that, even if the marginal cost of acquiring or transmitting information is zero, when firms incur fixed costs to transmit price information, all firms do not

3 This figure is based on NAICS classification code 443112, which is comprised of establishments known as consumer electronics stores primarily engaged in retailing new consumer-type electronic products. Source: U.S. Census Bureau, 1997 Economic Census, January 5, 2001, p. 217.

${ }^{4}$ This figure probably understates the actual number of potential competitors in on-line consumer electronic products markets, as the up-front cost to being an e-retailer is lower than being a "brick and mortar" retailer.

${ }^{5}$ A number of recent papers have suggested that firms might avoid this outcome by price discriminating to take advantage of consumers' heterogeneities (Baylis and Perloff, 2002) or obfuscating price information (Ellison and Ellison, 2001). Recently, Baye, Morgan, and Scholten $(2001,2002,2003)$ provide empirical evidence that the levels of dispersion observed at Shopper.com cannot be entirely explained by these considerations.

${ }^{6}$ This assumes that arbitrage prevents firms from price discriminating among consumers who visit their firm directly and those who "click through" from a price comparison site. For a theoretical analysis of the impact of price discrimination on price dispersion, see Baye and Morgan (2002). 
charge the same price in equilibrium. ${ }^{7}$ Moreover, a profit-maximizing gatekeeper, such as Shopper.com, will charge positive advertising fees to induce the profit-maximizing level of price dispersion. ${ }^{8}$

Section 2 shows that, in fact, a variety of oligopoly pricing models predict that different firms will continue to charge different prices for similar products even as Internet markets mature. In other words, one should expect price dispersion as a long-run equilibrium even in the seemingly "frictionless" world of the Internet. Moreover, these models predict that the value of the information provided by price comparison sites such as Shopper.com systematically depends on how many prices are listed for each product.

Section 3 uses data from Baye, Morgan, and Scholten (2001) to estimate the value of information at an online price comparison site. These data include nearly 4 million daily price observations from Shopper.com - a leading price comparison site for electronics products. We find that, over an 8-month period between 2000 and 2001, the value of the price information that Shopper.com provided to consumers on over 1,000 top-selling electronics products remained stable at about 16 percent: Consumers using this site save an average of 16 percent on purchases compared to those purchasing from a representative store. Consistent with a variety of theories, we also find that the value of information depends on the size of the market. When

\footnotetext{
7 This result holds even when firms can price discriminate between consumers who do and do not use a price listing service; see Baye and Morgan (2002).

8 Adding more complicated search strategies does not eliminate price dispersion. See, for example, Stahl (1989), Janssen and Moraga (2000), and Gatti (2000).
} 
two firms list prices, consumers save $11 \%$ by purchasing at the lowest price rather than the average price. These savings jump to $20 \%$ when more than 30 firms list prices.

From the standpoint of public policy and marketing, our results suggest that price comparison services such as Shopper.com, Nextag.com, and Kelkoo.com provide substantial value to consumers, and that this value will be enhanced over time as additional firms use e-tail distribution channels. However, this potential value accrues to consumers with Internet access and not to those on the "wrong side" of the "digital divide." We conclude in Section 4, and discuss some limitations with the present analysis and how these might be addressed in future research.

\section{Economic Models of Internet Pricing}

As noted by Baye, Morgan, and Scholten (2001), the Shopper.com price comparison site is best viewed as an information "clearinghouse," "gatekeeper," or a "price listing service" where consumers can observe (virtually costlessly) all of the listed prices. A number of authors have analyzed this environment, including Shilony (1977), Varian (1980), Rosenthal (1980), Narasimhan (1988), and more recently Baye and Morgan (2001). Each of these analyses assumes that identical firms sell to two-types of consumers: Those who purchase at the best price listed at the comparison site, and those who do not. For example, in the Varian model, "informed consumers" purchase at the lowest price listed, while "uninformed consumers" purchase at the average listed 
price. In the Narasimhan model, consumers called "switchers" view all firms' products as homogeneous and purchase at the lowest price listed, while "brand loyal" consumers purchase from their preferred firm. Despite these modeling differences, all of the models predict that the prices charged by the firms are, in equilibrium, dispersed. In other words, firms do not all charge the same price, even if products are identical and firms have symmetric costs.

One measure of the value of the price information provided by a site like Shopper.com is the expected difference in prices paid by consumers with and without access to its list of prices. In the Varian model, consumers with access to a price listing service such as Shopper.com pay the lowest listed price, while consumers without access pay the average listed price. Thus, the value of information is the difference between the average price $(E p)$ and the expected minimum price $\left(E p_{\min }\right)$ listed at a price comparison site: $V=E p-E p_{\min }$.

There are several reasons to expect that the value of information might systematically depend on the number of firms listing prices at a price comparison site. First, in the classical competitive paradigm, an increase in the number of firms reduces the average price charged in the market. In the limit, competition forces all firms to charge the same price, so both $E p$ and $E p_{\min }$ converge to marginal cost and thus the value of information tends to zero as the number of firms gets large. Based on this, one might speculate that the value of information decreases as the number of firms listing prices increases. 
Second, consider a naïve model where firms do not react to competitive forces and in which the distribution of prices is fixed. In this case, the average price will be independent of the number of firms, but the expected minimum price will decline as the number of firms listing prices increases. Thus, in this naïve setting, one would expect the value of information, $V=E p-E p_{\min }$, to be an increasing function of the number of prices listed at the comparison site.

Finally, the oligopolistic models discussed earlier in this Section imply that the equilibrium distribution of prices (and hence, the value of information) depends on the number of firms listing prices. For example, if we let $n$ denote the number of firms listing prices and $I$ denote the fraction of "informed consumers," the distribution of prices $(p)$ in the Varian model is ${ }^{9}$

$$
G_{n}(p)=1-\left(\frac{(1-p)(1-I)}{n I p}\right)^{\frac{1}{n-1}} \text { on }\left[\left(\frac{1-I}{n I+(1-I)}\right), 1\right]
$$

Similar expressions may be derived for the Baye-Morgan and Narasimhan models. One can show that, for both the Baye-Morgan and Varian models, the value of information is greater with many firms listing prices than with few firms listing prices. ${ }^{10}$

The key point is that there are many reasons to expect the value of information to depend systematically on the number of firms listing prices:

$$
V(n)=E p(n)-E p_{\min }(n)
$$

\footnotetext{
${ }^{9}$ This particular expression for the distribution of prices assumes that each consumer wishes to purchase one unit of the product and has a reservation price $r=1$.

10 The Shilony, Rosenthal, and Narasimhan models partition consumers into loyal and non-loyal customers rather than informed and uninformed consumers.
} 
For this reason, we will control for these potential effects in the results that follow.

\section{Data, Empirical Methodology, and Results}

We assembled a data set consisting of nearly 4 million price quotes for electronics products listed at Shopper.com. These data include daily prices for over 1,000 of the most popular electronics products listed between August 2000 and March 2001. While a more thorough discussion of the products covered and our collection methodology is contained in our companion paper (Baye, Morgan, and Scholten, 2001), it is useful to highlight a number of features that make these data particularly useful for the issues at hand.

Shopper.com is not a shopbot that searches the Internet for prices of consumer electronics products. Rather, it is a database of the prices different firms charge for identical electronics products. Consistent with the assumptions of the Baye-Morgan model, firms pay Shopper.com for the privilege of listing their prices in this database. ${ }^{11}$ The only cost to a consumer using the site is the few seconds it takes to click on the appropriate product category (such as cameras or printers) or to enter the name of a specific product (such as a Nikon Coolpix 990 or an HP LaserJet 1100xi). Once this is done, Shopper.com returns a list of the current prices charged by each firm in its database that sells the product. Importantly, these prices are presented in a

\footnotetext{
${ }^{11}$ Firms input their own prices into the database, so measurement error is not an issue. As noted by the referees, this is important since our regression models use ratios as the dependent variable.
} 
single list, so that even the relatively modest cost of searching different Internet sites for the best price is absent. ${ }^{12}$ Furthermore, by simply clicking the "Price" heading, a consumer can sort the firms from lowest to highest price, thereby making it virtually costless to secure the lowest available price. Over the period sampled, we found that Shopper.com provided more reliable price information than mySimon and other sites based on shopbot technologies. ${ }^{13}$

Shopper.com's parent company, Cnet.com, was among the top 10 most visited web sites during the period in which these data were collected, and first among consumer electronics web sites. ${ }^{14}$ Its next closest competitor at the time was mySimon.com, which Cnet acquired in March 2000. Its closest non-subsidiary competitor, Pricescan.com, was ranked 15th. Thus, Shopper.com is a high-traffic site where participating firms are serious enough about their e-retail presence to pay monthly fees to Cnet for the opportunity to list product prices in Shopper.com's database. ${ }^{15}$ The

\footnotetext{
${ }^{12}$ Of course, it is possible that the firm offering the lowest price on the entire Internet is not contained in the Shopper.com database and thus, to that extent, search costs are not completely eliminated. Nonetheless, search costs are substantially lower than for a consumer who does not have Internet access. See Ratchford (1980) for a study which shows that the value of information from search is low in conventional retail appliance markets.

${ }^{13}$ For instance, a search for a Palm V at mySimon returned a list consisting not only of the personal data assistant but also numerous accessories. In contrast, all items returned in the list at Shopper.com have identical part numbers. Since reliable estimates of the value of information critically depend on the homogeneity of the underlying products, our Shopper.com data is well-suited for the purposes at hand. We note, however, that recent advances in shopbot technology make this less of an issue today than during the period in which our data were collected.

${ }^{14}$ According to 100hot.com's Most Visited Web Sites, January 18, 2000.

${ }^{15}$ At the beginning of our sample, firms wishing to list a product on Shopper.com's site paid a fixed monthly fee per product, plus a marginal fee if the number of "qualified leads" exceeded some threshold (where a qualified lead is defined as a consumer clicking to the firm's site from the Cnet site).
} 
authors of this paper have now purchased over 50 different products from low-priced merchants at Shopper.com, and in all instances the prices paid and products delivered met the advertised specifications exactly. Thus, unlike some markets where obfuscation, reputation, gray market goods, price discrimination, or bait-and-switch tactics play a dominant role in explaining price dispersion, ${ }^{16}$ the Shopper.com environment would seem to approximate the institutional structure assumed in theoretical literature discussed in Section 2.

Table 1 provides summary statistics for these data. The average price ${ }^{17}$ of a product in our sample is $\$ 513.19$, and the average minimum price charged is $\$ 457.57$. The number of firms listing prices ranges from one to over 60, with an average of 17.27 prices listed across all of the product-dates. Notice that the average range in prices is $\$ 123.43$. Thus, despite the fact that shoppers can purchase at the lowest

${ }^{16}$ A host of papers show that these issues are important in many markets. Brynjolfsson and Smith (2000b) find that shopbot technologies tend to weaken branded retailers, yet these retailers still have a $3.1 \%$ to $6.8 \%$ margin advantage over competitors. For other issues pertaining to branding, see Bergen, Dutta, and Shugan (1996) and Ward and Lee (2000); for bundling issues, see Bakos and Brynjolfsson (2000). Baye, Morgan, and Scholten (2002) find that the premium retailers are able to charge by participating in internal certification programs offered by Shopper.com vary with the number of other firms that use these services. For instance, when a single retailer is the only retailer participating in the certification program, it can charge a premium of about 20 percent. When more than three firms in a particular market use these programs or services, the premium vanishes. In an Internet auction environment, Resnick and Zeckhauser (2002) find that sellers with better reputations were more likely to sell the item being auctioned. Resnick et al. (2002) find that reputable sellers on eBay earn a premium of about 7.6 percent. For a theoretical analysis of eBay-like reputation systems, see Dellarocas (2001). Ellison and Ellison (2001) find that retailers selling computer memory employ loss leader or bait-and-switch tactics to increase profits.

17 Prices are exclusive of shipping costs. Elsewhere (Baye, Morgan, and Scholten, 2003), we provide evidence that shipping costs at Shopper.com are quite small compared to list prices, and do not vary much across firms. Furthermore, there is no evidence of any systematic relationship between shipping costs and list prices. 
listed price by "clicking a mouse," there is considerable dispersion in prices.

\subsection{Value of Information}

For each product $k$ and date $t$ in our sample, our data includes the number of firms $\left(n_{k t}\right)$ listing prices for product $k$ on date $t$ and the prices charged by each of these firms. Letting $\bar{p}_{k t}$ denote the average price charged by the firms selling product $k$ on

date $t$, and $p_{k t}^{\min }$ denote the minimum price charged for product $k$ on date $t$, one could use

$$
\widehat{V\left(n_{k t}\right)}=\bar{p}_{k t}-p_{k t}^{\min }
$$

as an estimate of $V(n)$. Table 2 presents this measure of the value of information for the top 25 products sold on one date (January 17, 2001) in our sample. For instance, a consumer wishing to purchase the top ranked product on this date (a Compaq iPaq H3650 Pocket PC) would have saved $\$ 49.38$ by purchasing at the lowest price rather than the average price of $\$ 529.72$. The raw correlation between the value of information (in dollars) and the number of firms selling these 25 products is 66.5 percent.

An alternative approach permits us to make meaningful comparisons of the value of information across expensive and inexpensive products. In particular, our analysis is based on the following unit-free measure of the value of information for product $k$ on date $t$ :

$$
V O I_{k t}=\frac{\bar{p}_{k t}-p_{k t}^{\min }}{p_{k t}^{\min }}
$$


This measure represents the percentage savings that a user of Shopper.com on date $t$ enjoys by getting to purchase product $k$ at the lowest listed price rather than at the average listed price. The last column of Table 2 presents this measure of the value of information for the top 25 products in our sample on January 17, 2001. The raw correlation between the number of sellers and the percentage value of information is 44.3 percent.

More generally, Table 1 reveals that, averaged across all of the top 1000 products and all dates in our sample, the value of information provided by Shopper.com was 15.89 percent. This translates into savings of between $\$ 50$ and $\$ 70$ on a typical purchase. ${ }^{18}$ The value of information exceeded 7.68 percent on over 75 percent of the product-dates, and exceeded 18.83 percent on 25 percent of the product-dates.

Figure 1 provides a time series graph of the average value of information (VOI) based on data for the top 1000 products sold. Notice that the value of information is remarkably stable at about 16 percent. This is surprising in light of the significant turmoil among dot-com firms over this period.

Figure 2 illustrates that the average value of information for the top 1000 products varies, depending on the number of prices listed for the product. The value of information is about $11 \%$ when only two price quotes are provided, rises to about 15 percent when three prices are listed, and thereafter stabilizes at around 17 percent

${ }^{18}$ Brynjolfsson and Smith (2000a), provide empirical evidence that prices for books and CDs are between 9 and 16 percent lower in Internet markets than in traditional retail markets. For a broader array of products, Scholten and Smith (2002) find no evidence of systematically lower prices on the Internet compared to conventional retail markets. 
until it again increases sharply when more than 20 firms list prices.

\subsection{Econometric Results}

Figures 1 and 2, in conjunction with correlations based on the data summarized in Tables 1 and 2, seem to indicate that the value of information is greater when more firms list prices than when only a few do so. However, these tables and graphs do not account for dynamic changes in such key variables as the number of consumers or firms with Internet access, costs, reservation prices, or differences in products (such as product popularity). In order to control for these potentially important effects, we also used a simple econometric model to study the relationship between the value of information $(V O I)$ and the number of firms listing prices for different products. We report results for a variety of specifications that attempt to control for unobserved differences in demand, costs, and market structure. These dummy variables include 229 time dummies (these date fixed effects control for unobserved changes over time in the number of potential firms, the number of consumers with Internet access, as well as changes in Shopper.com's fee structure) as well as product rank dummies (these fixed effects provide a crude control for cross sectional variation due to factors like differences in the popularity or age of products). ${ }^{19}$ The econometric results from five different specifications are summarized in Table 3.

\footnotetext{
${ }^{19}$ Shopper.com provides an ordinal measure of the popularity of each product. For each day in our sample, products are ranked from 1 (most popular) to 1000 (least popular), based on Cnet ratings. Our dummy variables partition ranks from 1-100, 101-200, and so on.
} 
Model 1 is a simple regression of the value of information (VOI) on five categories for the number of prices listed. Notice that the estimated constant is zero by definition, since it represents the average value of information when only a single price is listed. These results indicate that the value of information is 14 percent when two to four prices are listed. The value of information increases to 17.8 percent when five to ten firms list prices. In instances where 11-20 or 21-30 firms list prices, the value of information falls to about 16.5 percent. Finally, when more than 30 prices are listed, the value of information is highest at 19.7 percent. The data suggest that the value of information is greater when many firms list the price of their product than when few firms do so. In particular, the estimated coefficients are lowest when 2 to 4 firms list prices, and highest when more than 30 firms list prices.

The second model in Table 3 adds product rank dummies to control for the impact of differences in product popularity on the value of information. This is motivated by the fact that parameters, such as reservation prices or inventory costs, can alter the distribution of prices and therefore the value of information. While the regression results for Model 2 reveal that it is indeed important to control for these effects, doing so does not qualitatively alter the finding that $V O I$ is greater when many firms list the price of their product than when few firms do so.

Model 3 replaces the five categories of the numbers of firms listing prices with a specific dummy for the number of firms listing prices to show that the findings reported in Models 1 and 2 are not an artifact of the groupings of the number of firms 
listing prices. The results in Model 3 indicate that the value of information is 11.4 percent when 2 firms list prices, compared to 19.7 percent when more than 30 firms list prices. Model 4 shows that these estimates are also robust to controls for product rank effects. While the estimated relationship between the value of information and number of listed prices in Models 3 and 4 are not monotonic, in both specifications the estimated value of information is lower when fewer than 30 firms list prices than when more than 30 firms list prices. Likewise, the coefficient estimates of the value of information are lowest when two or three firms list prices.

Model 5 is the most general specification. In addition to the 29 variables controlling for different numbers of firms, this regression includes 9 dummy variables to control for the effects of product popularity and also 229 dummies for each date in the sample to control for unobserved heterogeneity across product ranks and dates (the time dummies are suppressed in the table). Once again, even controlling for these cross-sectional and dynamic effects, the results summarized in Models 1 through 4 continue to hold..$^{20}$

Finally, it is interesting to note that, in all specifications reported in Table 3 that include product rank fixed effects, the coefficients on these product rank fixed effects are positive and statistically significant. Thus, controlling for dynamic and number of firm effects, we find that the value of information is lower for the most popular (top 100) products than for less popular products. This might stem from the presence

\footnotetext{
${ }^{20}$ For each specification we also conducted an $F$-test to test the joint hypothesis that the number of firms listing prices has no impact on the value of information. In all cases, we reject this null hypothesis at conventional levels of significance.
} 
of many other information sources (such as CNet Reviews, etc.) for these products, thereby making buyers of these products less inclined to infer quality from price.

\section{Concluding Remarks}

Over an eight-month period between 2000 and 2001, consumers could have saved an average of 16 percent by using the Shopper.com price comparison site. These savings represent the value of the price information provided by the site, and vary systematically with the number of firms listing prices. The value of information is about 11 percent when only two firms list prices, compared to about 20 percent when more than 30 firms list prices. However, these potential savings accrue only to consumers on the right side of the digital divide, who can easily find the lowest listed prices at Shopper.com. Expressed differently, a consumer on the wrong side of the digital divide would have to spend between 11 and 20 percent more to buy the consumer electronics equipment needed to bridge the divide, compared to consumers who already have access to Shopper.com. Our results suggest that future research focusing on the policy implications of this finding might be warranted.

Our analysis is only a first step and has a number of potential limitations. First, we have assumed that price is the sole determinant of consumers' purchase decisions. To the extent that firms differ with respect to service (speed of shipping, return policies, restocking fees) or reputation, our estimates may overstate the value of information.

Second, we derived the value of information by comparing the lowest price listed 
for a given product to the average price for that product offered by firms listing on the comparison site. While this is consistent with economic models such as Varian (1980), consumers lacking Internet access may sample an entirely different set of retailers. If prices in conventional retail markets differ systematically from prices in online markets, our estimates of the value of information will be misstated. We note that the empirical evidence about such differences is mixed, with some researchers finding online prices to be higher than conventional retail (Bailey, 1998b), some finding online prices to be lower (Brynjolfsson and Smith, 2000a), and still others finding little difference between the two (Scholten and Smith, 2002).

Finally, in assessing the relationship between the value of information and the number of competing firms, we ignored the fact that a firm simultaneously decides its price and whether to list it at Shopper.com. Thus, there is a potential endogeneity problem. In future research, it might be useful to instrument firms' decisions to list prices. 


\section{References}

[1] Bailey, Joseph P., Intermediation and Electronic Markets: Aggregation and Pricing in Internet Commerce. Ph.D. Thesis, Technology, Management and Policy, Massachusetts Institute of Technology, Cambridge, MA, 1998a.

[2] Bailey, Joseph P., "Electronic Commerce: Prices and Consumer Issues for Three Products: Books, Compact Discs, and Software," Organisation for Economic Co-Operation and Development, $O C D E / G D$ 98(4), 1998b.

[3] Bakos, Yannis and Erik Brynjolfsson, "Bundling and Competition on the Internet: Aggregation Strategies for Information Goods," Marketing Science (2000), 19 (1) pp. 63-82.

[4] Baye, Michael R. and John Morgan, "Information Gatekeepers on the Internet and the Competitiveness of Homogeneous Product Markets," American Economic Review (2001) 91(3), pp. 454-474.

[5] Baye, Michael R. and John Morgan, "Information Gatekeepers and Price Discrimination on the Internet," Economic Letters (2002) 76, pp. 47-51.

[6] Baye, Michael R., John Morgan, and Patrick Scholten, "Price Dispersion in the Small and in the Large: Evidence from an Internet Price Comparison Site," mimeo, July 2001. 
[7] Baye, Michael R., John Morgan, and Patrick Scholten, "Pricing and Reputation in an Online Consumer Electronics Market," mimeo, 2002.

[8] Baye, Michael R., John Morgan, and Patrick Scholten, "Persistent Price Dispersion in Online Markets," in The New Economy, The University of Chicago Press, forthcoming 2003.

[9] Baylis, Kathy and Perloff, Jeffrey M., "Price Dispersion on the Internet: Good Firms and Bad Firms," Review of Industrial Organization, forthcoming 2002.

[10] Bergen, Mark, Shantanu Dutta, and Steven M. Shugan, "Branded Variants: A Retail Perspective," Journal of Marketing Research (1996) 33, pp. 9-19.

[11] Brown, Jeffrey R. and Austan Goolsbee, "Does the Internet Make Markets More Competitive? Evidence from the Life Insurance Industry," Journal of Political Economy (2002) 110(3), pp. 481-507.

[12] Brynjolfsson, Erik and Michael D. Smith, "Frictionless Commerce? A Comparison of Internet and Conventional Retailers." Management Science (2000a) 46(4), pp. 563-585.

[13] Brynjolfsson, Erik and Michael D. Smith, "The Great Equalizer? Consumer Choice Behavior at Internet Shopbots." MIT Working Paper, $2000 \mathrm{~b}$. 
[14] Clay, Karen, Ramayya Krishnan, and Eric Wolff, "Prices and Price Dispersion on the Web: Evidence from the Online Book Industry," National Bureau of Economic Research Working Paper \#8271, May 2001.

[15] Clay, Karen, and Choon Hong Tay, "Cross-Country Price Differentials in the Online Textbook Market," mimeo, 2000.

[16] Clemons, Eric K., Il-Horn Hann, Lorin M. Hitt, "The Nature of Competition in Electronic Markets: An Empirical Investigation of Online Travel Agent Offerings," mimeo, 2000.

[17] Dellarocas, Chrysanthos, "Building Trust Online: The Design of Reliable Reputation Reporting Mechanisms for Online Trading Communities." MIT Sloan School of Management Working Paper, July 2001.

[18] Ellison, Glenn and Sara Fisher Ellison, "Search, Obfuscation, and Price Elasticities on the Internet." mimeo, 2001.

[19] Gatti, J. Rupert J., "Equilibrium Price Dispersion with Sequential Search." mimeo, 2000.

[20] Janssen, Maarten and Jose Luis Moraga, "Pricing, Consumer Search and the Size of Internet Markets.” mimeo, June 2000.

[21] Morton, Scott Fiona, Florian Zettelmeyer, Jorge Silva-Risso, "Internet Car Retailing." Journal of Industrial Economics 49 (4), 2001, pp. 501-519. 
[22] Narasimhan, Chakravarthi, "Competitive Promotional Strategies." Journal of Business, (1988) 61, pp. 427-449.

[23] Pan, Xing, Brian T. Ratchford, and Venkatesh Shankar, "Why Aren't the Prices of the Same Item the Same at Me.com and You.com?: Drivers of Price Dispersion Among E-Tailers." mimeo, November 2001.

[24] Ratchford, Brian T., "The Value of Information for Selected Appliances," Journal of Marketing Research (1980), 17, pp. 14-25.

[25] Resnick, Paul and Richard Zeckhauser, "Trust Among Strangers in Internet Transactions: Empirical Analysis of eBay's Reputation System," Advances in Applied Microeconomics, forthcoming 2002.

[26] Resnick, Paul, Richard Zeckhauser, John Swanson, and Kate Lockwood, "The Value of Reputation on eBay: A Controlled Experiment," mimeo, 2002.

[27] Rosenthal, Robert W., "A Model in Which an Increase in the Number of Sellers Leads to a Higher Price," Econometrica (1980) 48(6), pp. 1575-1580.

[28] Scholten, Patrick and Adam Smith, "Price Dispersion Then and Now: Evidence from Retail and E-tail Markets," Advances in Applied Microeconomics, forthcoming 2002.

[29] Shilony, Yuval, "Mixed Pricing in Oligopoly," Journal of Economic Theory (1977) 14, pp. 373-388. 
[30] Smith, Michael D. "The Law of One Price? Price Dispersion and Parallel Pricing in Internet Markets," mimeo, 2001.

[31] Stahl, Dale O. II., "Oligopolistic Pricing with Sequential Consumer Search," American Economic Review (1989) 79(4), pp. 700-712.

[32] Stigler, George J. "The Economics of Information," Journal of Political Economy (1961) 69(3), pp. 213-225.

[33] Varian, Hal, "A Model of Sales," American Economic Review (1980) 70, pp. 651-659.

[34] Ward, Michael R. and Michael J. Lee, "Internet Shopping, Consumer Search and Product Branding." Journal of Product and Brand Management (2000) 9(1), pp. $6-18$. 
Table 1: Summary Statistics

\begin{tabular}{lrrr}
\hline \hline & Average* $^{*}$ & $\begin{array}{r}\mathbf{2 5}^{\text {th }} \\
\text { Percentile }\end{array}$ & $\begin{array}{r}\mathbf{7 5}^{\text {th }} \\
\text { Percentile }\end{array}$ \\
\hline Number of Firms Listing Prices & 17.27 & 7 & 26 \\
Price & $\$ 513.19$ & $\$ 93.69$ & $\$ 489.65$ \\
Minimum Price & $\$ 457.57$ & $\$ 82.95$ & $\$ 435.00$ \\
Price Range & $\$ 123.43$ & $\$ 17.95$ & $\$ 110.61$ \\
Percentage Range** $^{*}$ Percentage Value of Information*** & $35.52 \%$ & $17.10 \%$ & $43.13 \%$ \\
& $15.89 \%$ & $7.68 \%$ & $18.83 \%$ \\
\hline & & & \\
Total No. of Daily Price Observations & $3,939,690$ & & \\
Total Product Dates & 228,080 & & \\
& & & \\
\hline \hline
\end{tabular}

${ }^{*}$ Average, giving equal weight to each product and date in the sample.

${ }^{* *}$ Price range for a product-date, divided by the minimum price.

${ }^{* * *}$ Difference between average and minimum prices for a product-date, divided by the minimum price. 
Table 2: Number of Sellers and Value of Information for the Top 25 Products Sold on January 17, 2001

\begin{tabular}{|c|c|c|c|c|c|}
\hline $\begin{array}{r}\text { Product } \\
\text { Rank }\end{array}$ & Product & $\begin{array}{r}\text { Number of } \\
\text { Sellers }\end{array}$ & $\begin{array}{r}\text { Average } \\
\text { Price }\end{array}$ & $\begin{array}{r}\text { Value of } \\
\text { Information } \\
\text { (\$) }\end{array}$ & $\begin{array}{r}\text { Value of } \\
\text { Information } \\
\text { (Percent) }\end{array}$ \\
\hline 1 & Compaq iPaq H3650 Pocket PC & 18 & $\$ 529.72$ & $\$ 49.38$ & $10.28 \%$ \\
\hline 2 & Palm Vx & 38 & $\$ 392.58$ & $\$ 35.81$ & $10.04 \%$ \\
\hline 3 & Plextor PlexWriter 12/10/32A CD-RW & 35 & $\$ 238.84$ & $\$ 34.34$ & $16.79 \%$ \\
\hline 4 & Palm V & 12 & $\$ 324.18$ & $\$ 31.55$ & $10.78 \%$ \\
\hline 5 & Nikon Coolpix 990 & 64 & $\$ 850.72$ & $\$ 105.72$ & $14.19 \%$ \\
\hline 6 & Palm IIIxe & 35 & $\$ 238.28$ & $\$ 38.29$ & $19.14 \%$ \\
\hline 7 & AMD ATHLON-1GHZ 384K CACHE SOCKA PGA 462 TBIRD 1GHZ & 23 & $\$ 244.89$ & $\$ 34.90$ & $16.62 \%$ \\
\hline 8 & Asus A7V (Socket A) & 14 & $\$ 149.63$ & $\$ 12.63$ & $9.22 \%$ \\
\hline 9 & Olympus D-460 Zoom & 54 & $\$ 359.92$ & $\$ 70.92$ & $24.54 \%$ \\
\hline 10 & Nikon Coolpix 950 & 56 & $\$ 749.52$ & $\$ 89.53$ & $13.57 \%$ \\
\hline 11 & Kodak DC280 Zoom & 12 & $\$ 501.28$ & $\$ 112.33$ & $28.88 \%$ \\
\hline 12 & Palm IIlc & 39 & $\$ 320.46$ & $\$ 40.51$ & $14.47 \%$ \\
\hline 13 & Sonicblue Multimedia Rio PMP300 MP3 Player & 8 & $\$ 161.05$ & $\$ 9.60$ & $6.34 \%$ \\
\hline 14 & NOMAD JUKEBOX AUDIO PLAYER 6GB SILVER & 33 & $\$ 449.05$ & $\$ 50.05$ & $12.54 \%$ \\
\hline 15 & Dell Dimension 4100 (866 MHz 17 inch monitor Office 2000 SBE) & 2 & $\$ 1,188.00$ & $\$ 0.00$ & $0.00 \%$ \\
\hline 16 & Canon PowerShot S100 & 48 & $\$ 456.44$ & $\$ 63.45$ & $16.15 \%$ \\
\hline 17 & Olympus D-360L & 52 & $\$ 269.93$ & $\$ 41.94$ & $18.40 \%$ \\
\hline 18 & Olympus C-3030 Zoom & 58 & $\$ 883.57$ & $\$ 155.57$ & $21.37 \%$ \\
\hline 19 & Sony Cyber Shot DSC-S70 & 53 & $\$ 724.96$ & $\$ 84.97$ & $13.28 \%$ \\
\hline 20 & Olympus D-490 Zoom & 48 & $\$ 450.10$ & $\$ 68.11$ & $17.83 \%$ \\
\hline 21 & Palm IIle & 11 & $\$ 157.42$ & $\$ 18.42$ & $13.25 \%$ \\
\hline 22 & Abit KT7 (Socket A) & 13 & $\$ 144.97$ & $\$ 15.97$ & $12.38 \%$ \\
\hline 23 & UPG ADOBE PHOTOSHOP 6.0 4.0/5.5 95/98/WME/NT4/W2K & 27 & $\$ 188.79$ & $\$ 17.84$ & $10.43 \%$ \\
\hline 24 & Canon PowerShot S10 & 41 & $\$ 445.48$ & $\$ 91.49$ & $25.84 \%$ \\
\hline 25 & Palm VIIx & 40 & $\$ 392.74$ & $\$ 44.74$ & $12.86 \%$ \\
\hline
\end{tabular}


Dependent variable: Value of Information. The sample is drawn from Shopper.com for the period 2 August, 2000 to March 31, 2001. Each model estimates an OLS regression of the dependent variable on market and product variables obtained from Shopper.com. Coefficients on date fixed effects are suppressed. Asymptotic $t$-statistics are reported in parentheses (to the right).

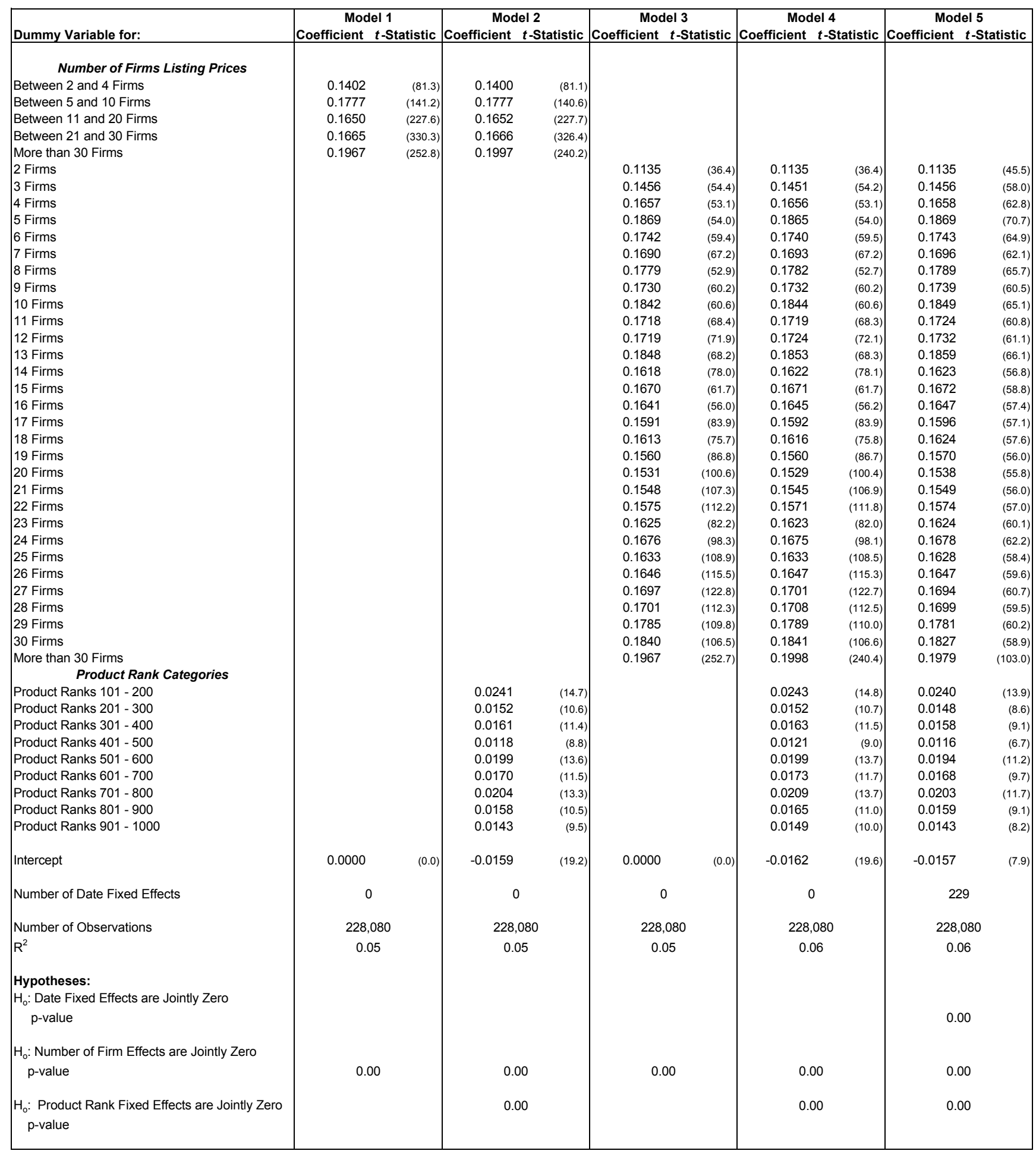


Figure 1: Average Value of Information Over Time

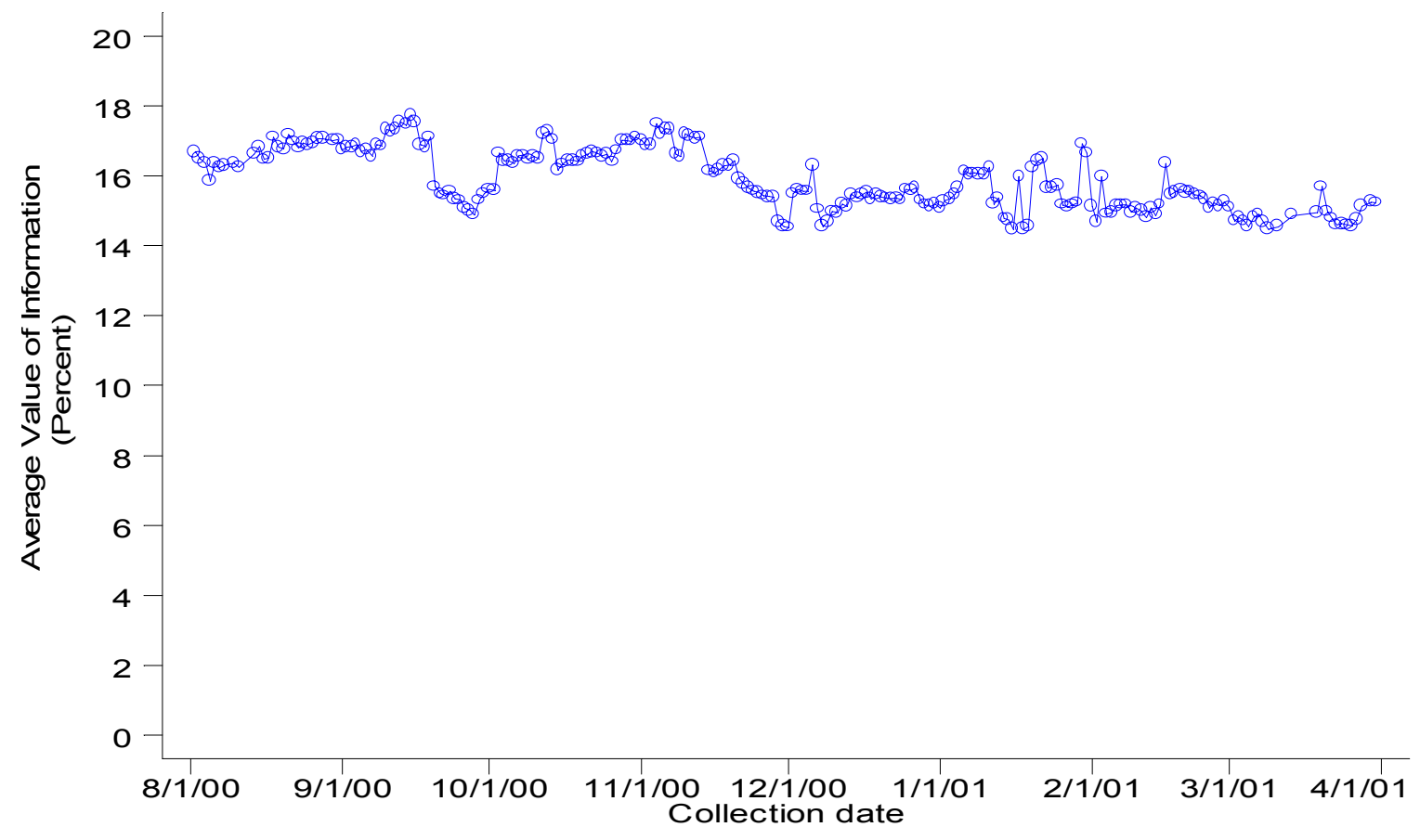


Figure 2: Average Value of Information by Number of Firms

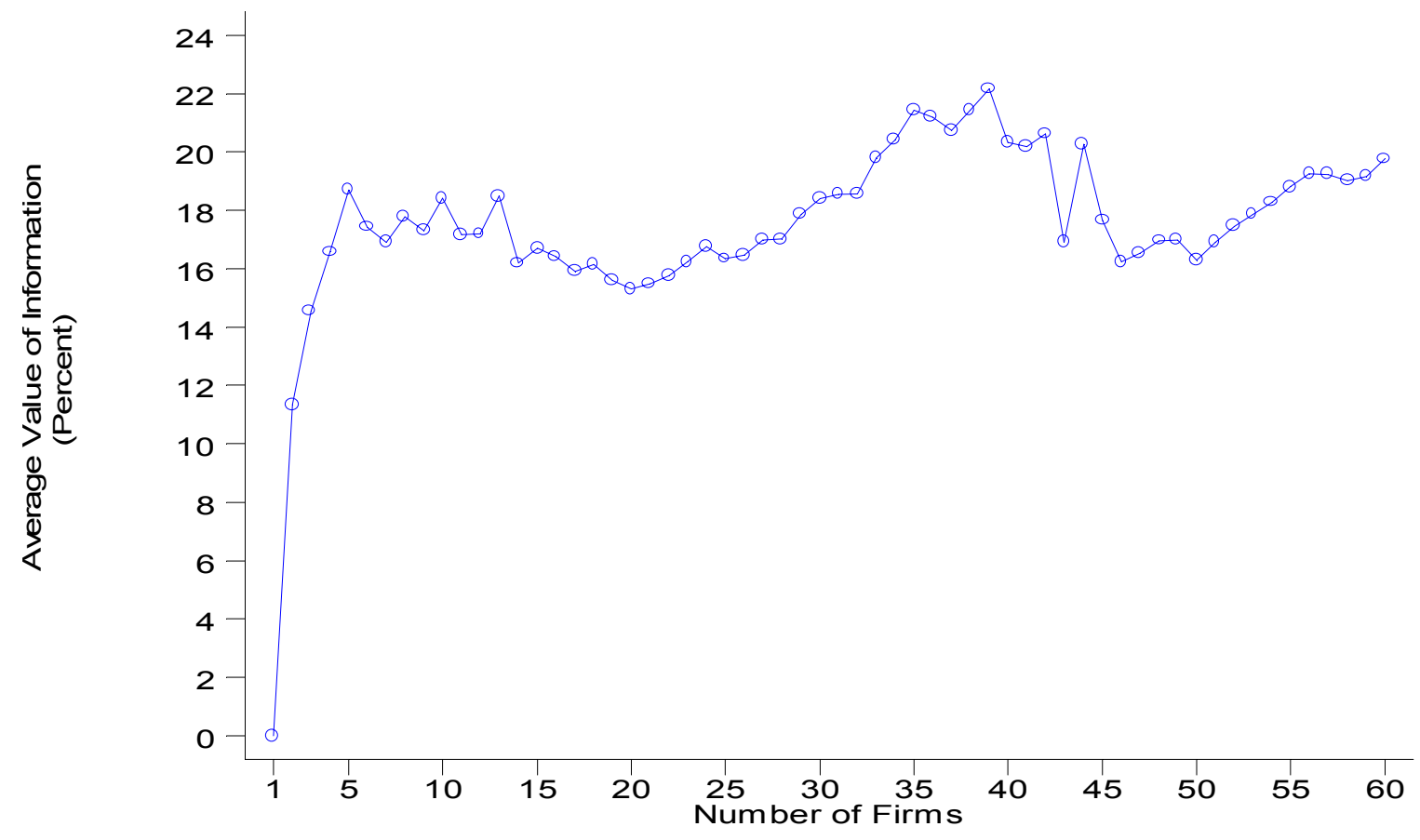

